peptide) reduces plasma endothelin-1 levels in patients with decompensated congestive heart failure. Am J Cardiol. 2002;90:435-8.

6. Truong KM, Bernabei AF, Czerska B. Nesiritide use in end stage heart failure. J Heart Lung Transplant. 2003;22:1S:113.

7. Tann SM. B-Natriuretic peptide improves hemodynamics and renal function in heart transplant patients immediately after surgery. $J$ Heart Lung Transplant. 2003;22:1S:S257.

8. Moazami N, Damiano RJ, Bailey MS, Hess RL, Lawton JS, Moon MR, et al. Nesiritide (BNP) in the management of postoperative cardiac patients. Ann Thorac Surg. 2003;75:1974-6.

\title{
Transit-time flow measurement cannot detect wrong anastomosis of an internal thoracic artery with the cardiac vein in coronary artery surgery
}

\author{
Yoshiyuki Takami, MD, and Hiroshi Masumoto, MD, Kasugai, Japan
}

I n coronary artery surgery transit-time flow measurement is useful to determine graft patency and to detect graft failure intraoperatively. Previous reports have demonstrated the accuracy and reproducibility of this noninvasive and simple procedure. ${ }^{1-5}$ In this report, however, we describe a case of wrong anastomosis of the left internal thoracic artery (LITA) with the cardiac vein, which could not be detected with transit flow measurement.

\section{Clinical Summary}

A 72-year-old man with effort angina was referred for coronary artery surgery. His coronary angiograms revealed occlusion of the distal right coronary artery and significant stenosis of the left main stem, the proximal left anterior descending artery, and the proximal left circumflex artery. He underwent triple coronary artery bypass grafting during cardiopulmonary bypass. The LITA was grafted to the left anterior descending artery, the left radial artery to the obtuse marginal branch of the left circumflex artery, and the saphenous vein to the atrioventricular branch of the right coronary artery. The result of transit-time flow measurement of the LITA graft is demonstrated in Figure 1. The mean flow (Qm) was 48 $\mathrm{mL} / \mathrm{min}$, the pulsatility index ([Maximal flow - Minimal flow]/ $Q m$ ) was 1.6, and the percentage of insufficiency (Volume of backward flow/Volume of forward flow) was $0 \%$. The postoperative angiogram revealed that the LITA had been anastomosed with the cardiac vein (Figure 1, $B$ ), although both aorta-coronary grafts (radial artery and saphenous vein) were patent.

\footnotetext{
From the Division of Cardiovascular Surgery, Kasugai Municipal Hospital, Kasugai, Japan.

Received for publication Jan 29, 2004; accepted for publication Feb 23, 2004.

Address for reprints: Yoshiyuki Takami, MD, Division of Cardiovascular Surgery, Kasugai Municipal Hospital, 1-1-1 Takagi-cho, Kasugai City 486-8510, Japan (E-mail: cvs@ hospital.kasugai.aichi.jp).

J Thorac Cardiovasc Surg 2004;128:629-31

$0022-5223 / \$ 30.00$

Copyright $\odot 2004$ by The American Association for Thoracic Surgery

doi:10.1016/j.jtcvs.2004.02.032
}

\section{Discussion}

In the transit-time method it is neither necessary to know the vessel diameter nor to perform any complex calibrating procedures. Therefore intraoperative transit-time flow measurement has become increasingly popular to check the anastomotic quality in coronary artery bypass grafting. ${ }^{5}$ As we have already demonstrated in the quantitative angiographic evaluation, ${ }^{2,3}$ intraoperative $\mathrm{Qm}$ is closely related to the degree of the stenosis at the most stenotic portion of the anastomosis. However, we cannot completely rely on the Qm value to determine the anastomotic quality of the graft. It is possible to have a patent anastomosis with a low Qm because the optimal Qm varies with the dynamic character, including blood pressure, heart rate, coronary resistance, and graft diameter. ${ }^{1,5} \mathrm{We}$ cannot necessarily judge a graft with a Qm of less than $20 \mathrm{~mL} / \mathrm{min}$ as nonpatent in the operating room. In contrast, surgeons can consider a graft with a Qm of greater than $20 \mathrm{~mL} / \mathrm{min}$ as patent. ${ }^{1}$ In addition, on the basis of the specific physiology of coronary circulation, patent graft flow is predominantly diastolic, forming a trapezoid-shaped waveform with a short systolic peak, as demonstrated in Figure 2. On the contrary, there is no diastolic flow in an occluded graft. ${ }^{2-4}$

In the patient in this report, the intraoperative Qm of the LITA was $48 \mathrm{~mL} / \mathrm{min}$, and its flow pattern was diastolic dominant. We considered the LITA as patent in the operating room. However, the postoperative angiogram revealed that the LITA had been accidentally anastomosed with the cardiac vein and not with the left coronary artery that we had intended to use for anastomosis. The arteriovenous flow pattern is similar to the arterioarterial flow pattern in coronary circulation. Although it is uncommon to perform incorrect grafting of the LITA to the cardiac vein, we should know that the transit-time flow measurement cannot differentiate the wrong anastomosis.

\section{References}

1. Jaber SF, Koenig SC, BhaskerRao B, et al. Role of graft flow measurement technique in anastomotic quality assessment in minimally invasive CABG. Ann Thorac Surg. 1998;66:1087-92.

2. Takami $\mathrm{Y}$, Ina $\mathrm{H}$. A simple method to determine anastomotic quality of coronary artery bypass grafting in the operating room. Cardiovasc Surg. 2001;9(5):499-503.

3. Takami Y, Ina H. Relation of intra-operative flow measurement with post-operative quantitative angiographic assessment of coronary artery bypass grafting. Ann Thorac Surg. 2001;72:1270-4. 
(B)

(A)
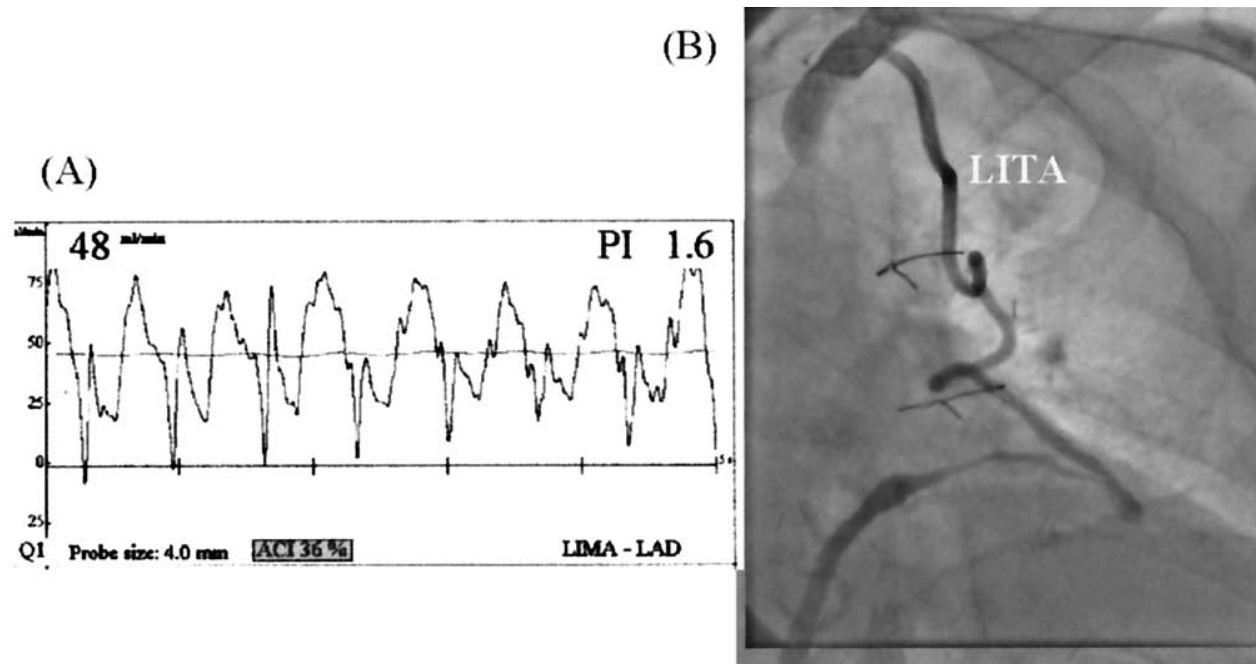

Cardiac vein

Figure 1. A, An intraoperative flow tracing of an in situ LITA grafted to the left anterior descending artery (LAD) in a 72-year-old man. The mean flow was $48 \mathrm{~mL} / \mathrm{min}$, the pulsatility index was 1.6, the percentage of insufficiency was $0 \%$, and the flow was predominantly diastolic, forming a trapezoid-shaped waveform with a short systolic peak. B, A postoperative angiogram showing the LITA anastomosed wrongly with the cardiac vein.

(B)

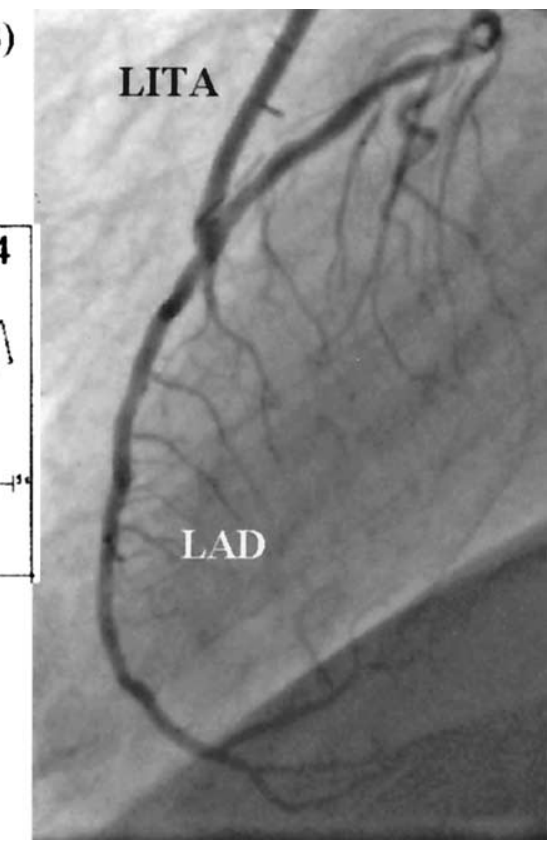

Figure 2. A, An intraoperative flow tracing of an in situ LITA grafted to the left anterior descending artery (LAD) in a 62-year-old man. The mean flow was $48 \mathrm{~mL} / \mathrm{min}$, the pulsatility index was 1.4, the percentage of insufficiency was $0 \%$, and the flow was predominantly diastolic, forming a trapezoid-shaped waveform with a short systolic peak. B, A postoperative angiogram showing the patent LITA anastomosed correctly to the left anterior descending artery. 
4. Morota T, Duhaylongsod FG, Burfeind WR, Huang CT. Intraoperative evaluation of coronary anastomosis by transit-time ultrasonic flow measurement. Ann Thorac Surg. 2002;73:1446-50.
5. Schmitz C, Ashraf O, Schiller W, et al. Transit time flow measurement in on-pump and off-pump coronary artery surgery. J Thorac Cardiovasc Surg. 2003;126:645-50.

\title{
Acromegaly caused by ectopic growth hormone-releasing hormone secretion by a carcinoid bronchial tumor: A rare entity
}

\author{
Kalliopi Athanassiadi, MD, ${ }^{a}$ Dimitrios Exarchos, MD, ${ }^{\mathrm{b}}$ Stylianos Tsagarakis, MD, ${ }^{\mathrm{c}}$ and Ion Bellenis, MD, ${ }^{\mathrm{a}}$ Athens, Greece
}

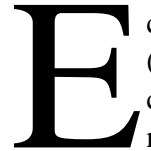
ctopic secretion of growth hormone-releasing hormone (GHRH) is a rare cause of acromegaly. ${ }^{1-5}$ The most common tumors secreting GHRH are bronchial carcinoids and pancreatic islet cell tumors. Differential diagnosis of pituitary adenoma is necessary to avoid unnecessary pituitary surgery and damage to the pituitary gland. Rarely, that syndrome is secondary to a carcinoid bronchial tumor. We present a case of a synchronous GHRH-secreting bronchial carcinoid and a pituitary adenoma in a patient with acromegaly.

\section{Clinical Summary}

A 37-year-old man who presented with an acromegaly over the last 8 -year period was hospitalized in our department. He had been treated surgically for an acidophil pituitary adenoma 1 year ago, and the histology had revealed an adenoma $(1.3 \mathrm{~cm} \times 1.3 \mathrm{~cm})$ producing growth hormone $(\mathrm{GH})$ and prolactin. There was no amelioration of the clinical signs of acromegaly postoperatively, and the GH and insulin-like growth factor levels, although lower, reached $50 \mathrm{ng} / \mathrm{mL}$ and $833 \mathrm{ng} / \mathrm{mL}$, respectively. The glucose tolerance test indicated diabetes. Thyroid and parathyroid hormones were within normal levels.

The patient was subjected to magnetic resonance imaging, which showed remaining pathologic pituitary tissue. Sandostatin was administered in subcutaneous doses of $100 \mu \mathrm{g} 3$ times because during the test of somatostatin, there had been a tremendous suppression of GH levels. The response to sandostatin was remarkable, but acromegaly was still active, and the patient was submitted to radiation of the pituitary region with Co60 in a total dose of 5000 Gy (200 Gy daily).

Six months later, the patient was re-examined and was found to still have active acromegaly while receiving medication. His chest $\mathrm{x}$-ray film demonstrated a large tumor of the left lung. Computed

\footnotetext{
From the Departments of Thoracic Surgery, ${ }^{\mathrm{a}}$ Radiology, ${ }^{\mathrm{b}}$ and Endocrinology, "Evangelismos" General Hospital, Athens, Greece.

Received for publication Nov 17, 2003; revisions received Jan 30, 2004; accepted for publication Feb 5, 2004.

Address for reprints: Kalliopi Athanassiadi, MD, Konstantinoupoleosstr. 34A Holargos, 15562 Athens, Greece (E-mail: kallatha@otenet.gr).

J Thorac Cardiovasc Surg 2004;128:631-2

$0022-5223 / \$ 30.00$

Copyright $\odot 2003$ by The American Association for Thoracic Surgery

doi:10.1016/j.jtcvs.2004.02.033
}

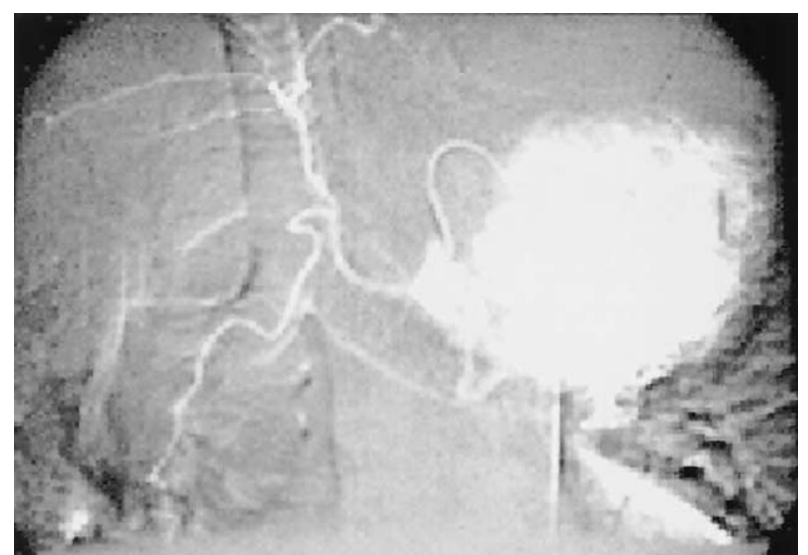

Figure 1. Angiography demonstrating a rich vascularized carcinoid tumor.

tomographic scanning revealed a large circumscribed tumor in the left upper lobe without lymph node enlargement. Angiography was undertaken before surgical intervention to exclude angioma or arteriovenous malformation (Figure 1). The patient underwent a left upper lobectomy (Figure 2). Histology demonstrated a carcinoid tumor of $6 \times 5.5 \times 4.5 \mathrm{~cm}$ without cellular atypia or any features of malignancy. The bronchial carcinoid was tested immunohistochemically and was found to be positive for gastrin and somatostatin secretion.

One month later, the basal GH levels decreased to $3.5 \mathrm{ng} / \mathrm{mL}$, the amelioration of the clinical signs was obvious, and the patient recovered completely within 6 months.

\section{Discussion}

Acromegaly caused by ectopic GHRH secretion by carcinoids is a rare cause of GH hypersecretion. This diagnosis should be suspected in any case of proved acromegaly in which there is no clear evidence of pituitary adenoma. ${ }^{1}$ Of the 39 fully documented cases of acromegaly caused by extracranial tumors synthesizing GHRH recognized by Faglia and colleagues, ${ }^{3} 21$ were bronchial carcinoids. Occasionally, carcinoid and pituitary adenomas coexist as parts of a widespread pluriglandular syndrome. ${ }^{5}$

This case differs from the others described in the literature because apart from the bronchial carcinoid, a pituitary adenoma coexisted and not a hyperplasia, as is mentioned in other reports. ${ }^{4,5}$ 